\title{
When Analysts turn into Boxers: An Introduction to Pre-Sales Requirements Engineering
}

\author{
Christoph Oemig \\ Denkwerk.Metaebene, Germany \\ christoph.oemig@oemig.net
}

\begin{abstract}
The major goal of a pre-sales phase is to provide customers with a compelling offer that exactly fits their needs. For its creation not only sales but also requirements engineering activities take place. The latter are needed to translate the customers' needs to features, to efforts, and eventually to costs. Although this sounds like business as usual, compared to conventional requirements engineering, there are substantial differences: the pre-sales phase entails challenges (e.g., a limited duration, a steadily moving target or the supplier's pre-investment) having a tremendous impact on all of these activities. With their conventional approach requirements engineering professionals are doomed to fail. However, an appropriate requirements engineering approach for the pre-sales phase remains to be defined. To address this issue the principal idea is to investigate typical customer engagement types and to conduct a risk analysis revealing the details of the pre-sales phase's challenges. The results deliver the basis informing the design of a new and capable approach. This article contributes the resulting concept and tools for successful pre-sales requirements engineering. They provide the risk responses and exit criteria to the pre-sales phase's challenges. The proposed approach even turns analysts into "boxers" when tackling one of the most difficult pre-sales problems: the moving target.
\end{abstract}

Keywords: Pre-sales requirements engineering, box fighting, Miller Heiman sales approach.

\section{Introduction}

In software engineering, each development of a complex software system runs through the basic process comprising phases of definition, implementation, testing, and delivery (either sequentially or iteratively). The process step defining a software system is usually covered by the requirements engineering (RE) discipline. RE is defined as "a systematic and disciplined approach to the specification and management of requirements" [1] whereas requirements are defined as "a condition or capability needed by a user to solve a problem or to achieve an objective" [1]. The RE process typically includes the steps of elicitation, documentation, validation, consolidation, and management of requirements [2]. Approaches to do so have been around and discussed in literature for a long time. However, not each and every company or person is able to build their own software. Software development is a complex issue which is the reason why experts are chosen and paid for the job. This reveals a phase that is typically part of the software development process, but which has not been fully integrated into software engineering processes: the pre-sales or pre-contract phase [3]. The major goal of the pre-sales phase is to provide customers with a compelling offer that exactly fits their needs including an 
attractive price indication. In order to prepare this kind of offer not only sales but also requirements engineering activities have to take place. They are needed to learn about customer's business goals and needs and to translate them into product or service features. From the features the efforts are derived that are needed to calculate the price. However, in the presales phase these activities usually differ from "conventional" RE, since they encounter a unique set of conditions and risks [4]. Ignoring this fact leads to losing opportunities, i.e., literally wasting time and money! Everything in the pre-sales phase is a pre-investment. Customer contacts are scarce and strongly limited in time. Their requirements and the efforts thereof are often rather derived from assumptions than knowledge. At the same time, competitors are actively engaging the same customer. Most facts are unknown at this stage while the customer's conception of a solution is a constantly moving target. U-turns in the customer's decision making should not be a surprise, but anticipated.

Exactly these conditions have a strong impact on the overall RE procedure in the pre-sales phase: First, they restrict the set of eligible requirements engineering techniques. Second, they strongly impact the way how they can be applied. And third, they introduce substantial differences to settings requirements engineers are usually used to: a) the customers are always there and stay, b) there is sufficient time for needed activities, and c) the customers are accessible and willing to answer questions extensively to learn about all details while eliminating assumptions. Obviously, the pre-sales phase does not allow standard RE measures to be applied. However, an appropriate requirements engineering approach for the pre-sales phase remains to be defined. To address this issue the principal idea is to investigate typical customer engagement types and to conduct a risk analysis revealing the details of the pre-sales phase's challenges. The results deliver the basis informing the design of a new and capable approach.

This article contributes the resulting concept and tools referred to as pre-sales requirements engineering. It dissolves the separation of RE and sales with a combined approach for the presales phase. The procedure used is reflected by this article's sections. First, the pre-sales phase and customer engagement were investigated in more detail; second, a risk analysis of the presales phase was conducted to learn more about the challenges, which a requirements engineering professional has to face and the proposed approach has to address. Further, proper risk responses and exit criteria had to be found to support the effectiveness of the new approach. Here, the idea was to learn from the people who have encountered these challenges ever since - sales people. The Miller Heiman sales approach including its Conceptual Selling ${ }^{\circledR}$ was selected for this since it intuitively adheres to the core RE principles and ideas. Next, a gap analysis revealed the need to further address the challenge of moving targets completing the overall approach. Eventually this article concludes with insights on future work.

\section{The Pre-Sales Phase}

In order to create the best pre-sales RE approach it has to be understood, how customers and suppliers get together and under what conditions that occurs. Therefore the subsequent sections describe typical customer-supplier engagements as well as conditions and challenges that make the pre-sales phase special.

\subsection{Customer-Supplier Engagement Types}

In a real-world setup it is usually not the case that the customer is there from the start. The engagement of customers and suppliers happens in many different ways. Typical ones are: 1) the potential customer is approached by the supplier based on account management information, 2) the supplier facilitates lead generation to systematically generate new customer contacts, 3) the customer discloses a need and contacts the supplier to talk about it, or 4) a tender process or 
formal invitation is issued by the customer to selected suppliers to submit a bid on a certain topic.

In the first case, the suppliers actively monitor and approach their customer accounts for selling opportunities based on internal data they have gathered [7]. The second case of lead generation is used by suppliers to acquire new customers by actively arousing interest triggering customer contacts [8]. These leads move through the sales funnel where they are nurtured and monitored to be engaged by a sales team for conversion. The third case represents what people usually expect to be the most common procedure: the customer independently, i.e., not triggered by lead generation, approaches the supplier with a certain problem or need. However, nowadays it becomes increasingly the case that customers prepare or setup tender processes, or in the private sector, a Request for Proposal (RfP) where selected suppliers are invited to submit a bid or solution proposal on something the customer wants to procure [9]. The original reason for this procedure was to be fair and free of bribery and nepotism. As part of a RfP, the customer provides a description usually formulated as questions towards the expected solution grouped by topics (e.g., pricing, required changes, delivery, functional issues, non-functional issues) (cf. Figure 1). There may be free-form answers. Yet, sometimes scale classifications like "fully applicable", "applicable", or "not applicable" are used. As part of their solution proposal suppliers are expected to answer these questions in addition to providing an effort estimation and price indication. The focus of the process is clearly on making it easier for the customer. Usually a rather tight submission date is announced by when these answers are expected. Until submission suppliers are often admitted to a question and answer session open to all participating suppliers to resolve issues with the RfP. Yet, beyond that, usually no further customer contact is granted.

\begin{tabular}{|c|c|c|c|c|c|c|c|}
\hline \multirow{3}{*}{$\begin{array}{l}1 \\
2 \\
3 \\
4\end{array}$} & \multirow{2}{*}{\multicolumn{2}{|c|}{ RFP Questions- Technical }} & \multirow{3}{*}{$\begin{array}{l}\text { Dear Supplier, Please describe in the space beloy hov your } \\
\text { product addresses each requirement. Please be thorough } \\
\text { and ansyer all items }\end{array}$} & & & & \\
\hline & & & & \multicolumn{4}{|c|}{ Xxxx Staff Only } \\
\hline & \multicolumn{2}{|r|}{ Technical } & & Rating 1-5 & Weighting & Result & Comments \\
\hline 5 & 3 & Architecture & & & & & \\
\hline 6 & 3.111 & $\begin{array}{l}\text { List all of your products/applications required by XXXX to implement the } \\
\text { complete solution }\end{array}$ & & & & 0 & \\
\hline 7 & 3.112 & Does XXXX get access to the application source code? & & & & 0 & \\
\hline 8 & 3.113 & $\begin{array}{l}\text { If no to the above, do you place your code in escrow? How is the escrowed } \\
\text { version kept current? Who pays the cost of escrow? }\end{array}$ & & & & 0 & \\
\hline 9 & 3.114 & $\begin{array}{l}\text { List the programming languages/version used to develop each application(s) } \\
\text { and what version(s) are currently supported? If an application uses more than } \\
1 \text { language - break out by function/component. }\end{array}$ & & & & 0 & \\
\hline 10 & 3.115 & $\begin{array}{l}\text { Describe your technical (infrastructure) architecture. Include diagrams for } \\
\text { additional clarity and support. }\end{array}$ & & & & 0 & \\
\hline 11 & 3.117 & $\begin{array}{l}\text { Describe your application architecture. Include diagrams for additional clarity } \\
\text { and support. Do you have a specific recommendation for OS/Application } \\
\text { Server/Database, etc... for your product? }\end{array}$ & & & & 0 & \\
\hline 12 & 3.118 & $\begin{array}{l}\text { What hardware can your application run on or is required for your } \\
\text { application? }\end{array}$ & & & & 0 & \\
\hline 13 & 3.119 & $\begin{array}{l}\text { Operating Systems supported. Please answer Yes or No. If Yes, provide } \\
\text { Version and whether certified on } 64 \text { bit OS. }\end{array}$ & & & & 0 & \\
\hline 14 & 3.120 & Solution runs on IBM - AIX? & & & & 0 & \\
\hline 15 & 3.121 & Solution runs on MS Windows? & & & & 0 & \\
\hline 16 & 3.122 & Solution runs on Red Hat Linux? & & & & 0 & \\
\hline 17 & 3.123 & Solution runs on Sun Solaris? & & & & 0 & \\
\hline
\end{tabular}

Figure 1. Excerpt from the technical section of a Request for Proposal (RfP)

While direct customer contacts or sessions are quite common for the case of the first three engagement types they become rather scarce with the usage of RfPs. This makes it very hard for $\mathrm{RE}$ activities to occur and at the same time degrades RE professionals to subject matter experts knowing the product. Answering the questions results in a lot of guesswork and assumptions (strongly dependent on the quality of the RfP) concerning the customer's real needs. There is insufficient room for the big picture or more detailed explanations. The effort estimations and prices have to be based upon assumptions - a situation, suppliers feel very uncomfortable with. Searcy [10] names further disadvantages of the RfP process: the final provider is often already 
selected before the RfP is sent out, RfPs address only large companies with sufficient resources to answer them, and RfPs are only means of seeking the lowest price.

\subsection{Conditions \& Challenges}

The pre-sales phase involves many challenges that make it different from the post-sales phase. These can be either derived directly or indirectly from the aforementioned customer engagement types. Sales people are used to address them in one way or another. For requirements engineers they make the pre-sales phase hard to master. All of the conditions must be addressed by an appropriate pre-sales RE approach. From a project managers point of view they are nothing but risks since they endanger the outcome of the pre-sales phase. In general, risks are defined as "an uncertain event or condition that, if it occurs, has a positive or negative effect on the projects objectives" [11]. Addressing these challenges basically means developing appropriate risk responses. For the engagement types mentioned in Section 2.1, the following risks can be identified:

- Pre-investment (time/money): the pre-sales phase takes place at the expense of the potential supplier. This investment is lost if the deal is not closed on his end. All activities have to prove in advance that they are worth the effort.

- Competition: the pre-sales phase is shared with competitors. Thus differentiating oneself from the competition becomes substantial. Yet, ways to do so are determined by the customer and are usually strongly limited (if not even sometimes reduced to the price indications, see the risk below).

- The large unknown: especially at the beginning of a new relationship there is a large deal of assumptions and guessing on the one hand, causing a large revealing effort on the other hand. There is a lot of room for misunderstandings, false assumptions, the unsaid, the implicit, and the deliberately false. This directly impacts effort and price estimations.

- The customer might not be open and honest about his business details and his attitudes to every potential supplier due to the lack of trust or the lack of another incentive like an existing contract or long-term relation.

- The pre-sales phase is extremely fragile due to unknown customer feelings and attitudes. Reasons completely unrelated to the proposed technical or business details may abort the buying process. Feelings and attitudes have the potential to break deals even if the solution offered ranks best of breed.

- The pre-sales phase is strongly limited in time which makes coping with the large unknown even harder. This also especially affects customer contacts which in this case usually last not days but only up to a few hours.

- The pre-sales subject is a constantly moving target. Both, not only the potential supplier but also the customer learn a lot in the early stages and consequently adapt their earlier decisions. U-turns should be anticipated. A very large angle for decision making is rather sound and common at this point to find the best solution.

- For customer sessions and with respect to the time constraints it is extremely important not to have the wrong people attending. Otherwise it becomes a waste of time and a waste of money (cf. pre-investment situation).

- The same accounts for when there is a doubt about the seriousness of interest. Sometimes the customer's interest might be faked just to acquire some external proficiency or feedback for free (or rather at the supplier's expense). It must be possible to derive a discrepancy (i.e., a business reason or attitude) which urges the customer to find the solution.

- Wrong timing: when to contact the customer (derived from account analysis) has to be chosen carefully, especially when the customer did not ask for it. 
- In a RfP scenario the supplier might face incomprehensible questions or insufficient descriptions with no room for clarification at the same time. This may lead to an inappropriate or wrong proposal by the supplier.

- The customer might already have a predefined solution in mind unintentionally denying alternate ones. RfP documents are informed by a solution in mind. Yet, the underlying problems are not disclosed. This puts suppliers already in a difficult position especially when offering alternate, innovative, or unusual solutions to a given problem. In many cases suppliers are the subject matter expert and a RfP might contain a solution they would not suggest or disagree with.

- Limited customer access: with RfPs there is no direct communication with customers to clarify requirements. In a questions and answers session suppliers often refrain from asking questions since these are public and it would reveal to competitors who they compete with.

- Bargaining/Negotiating: the pre-sales phase involves a great deal of negotiation. All negotiation activities must ensure that the supplier is not the loser at the end, i.e., the outcome of the deal must be acceptable for the supplier.

- Reduction to price: the customer already has chosen a preferred solution and only wants to get the lowest price. This reduces the procedure to a mere price competition causing a disadvantage for value selling suppliers by taking away the means for their differentiation.

\subsection{Summary}

In the pre-sales phase the customer access has to be most important goal. Here, it is the most valuable and scarce asset. A supplier strategy's goal must be to facilitate and preserve direct customer access in order to allow RE activities to take place. Thus answering RfPs cannot be the preferred scenario. That also explains real-world observations where suppliers try to be in contact with customers before they issue a RfP. Suppliers try to influence the solution sought for in a favorable direction or to best skip the tender process entirely if possible.

Table 1 contains an overview of the pre-sales risks and shows how they affect RfPs and situations of direct customer contact.

Table 1. Risk overview of the pre-sales phase

\begin{tabular}{|c|c|c|}
\hline Risk & Direct customer contact situation & Request for Proposal (RfP) \\
\hline Pre-investment & $X$ & $x$ \\
\hline Competition & $x$ & $\mathrm{x}$ \\
\hline Large unknown & $x$ & $x$ \\
\hline Lack of trust & $x$ & \\
\hline Attitude \& feelings, phase fragility & $x$ & $\mathrm{X}$ \\
\hline Limited time & $x$ & $x$ \\
\hline Moving target & $x$ & $\begin{array}{l}\text { (even worse, the target is fix, see } \\
\text { predefined solution) }\end{array}$ \\
\hline $\begin{array}{l}\text { Wrong people, unknown organization \& } \\
\text { decision making }\end{array}$ & $x$ & \\
\hline Seriousness of interest & $\mathrm{X}$ & $\mathrm{X}$ \\
\hline Wrong timing & $x$ & \\
\hline Incomprehensible questions & & $\mathrm{X}$ \\
\hline Predefined solution & & $X$ \\
\hline Limited or no customer access & $\mathrm{x}$ & $\mathrm{X}$ \\
\hline Bargaining/Negotiation & $\mathrm{X}$ & (even worse, see reduced to price) \\
\hline Reduction to price & & $\mathrm{X}$ \\
\hline
\end{tabular}


While the risk situation in direct customer contact situations is tough, it becomes even worse in the case of a RfP. Pre-sales RE or any other RE approach can hardly take place effectively in a RfP scenario. Therefore the next sections will leave it aside and focus on direct customer contacts when developing an appropriate pre-sales RE approach.

\section{The Foundation of Pre-Sales Requirements Engineering - Sales}

The findings of the previous section strongly inform the pre-sales strategy's design. This section analyzes how sales people cope with the aforementioned challenges by introducing a sales approach that intuitively assimilated to RE practices from a sales perspective.

\subsection{The Miller Heiman Sales Approach}

Miller Heiman is one of the top five sales performance companies. It has been providing valuable insights to sales leaders for about the last four decades. Their Strategic Selling ${ }^{\circledR}$ [7] and Conceptual Selling ${ }^{\circledR}[5]$ approaches bundle their long-term sales expertise and experience into methods and tools. Strategic Selling ${ }^{\circledR}$ provides a framework for multiple customer interactions gathering feedback from several directions (allowing account analysis). It is used for finding and developing sales opportunities. This article focuses on Conceptual Selling ${ }^{\circledR}$ which aims at the individual sales session, i.e., direct customer contact and interaction.

In the pre-sales phase an adequate strategy basically defines two major parts: risk responses and exit criteria. Risk responses are actions to avoid, transfer, mitigate, or accept a given risk [11]. Exit criteria are the primary risk responses to the pre-investment risk. They describe conditions at which the supplier ought to quit the selling process. Overall, both of them are needed to secure the pre-investment, to eliminate uncertainty, to safeguard the sale's aftermath, and to get the most out of direct customer interaction.

The central objective of Conceptual Selling ${ }^{\circledR}$ is to determine the customer's concept. Customers typically want to achieve, fix, or avoid something for certain reasons. There is a discrepancy between where they are and where they would like to be. The approach distinguishes itself from others by explicitly seeking to find the reasons for this discrepancy first, before promoting a specific product or service. Its focus is rather on value selling than on price. However, this requires sales staff to listen carefully to the customer rather than to talk or persuade. Another important detail besides the buying reason are the buying influencers, i.e., the people behind the buying decision. It is very important to find out, who they are and their position towards the wanted solution since the "customer buys for her reasons, not yours" [5].

A sales session, i.e., an event, where customer and supplier meet, is comprised of three major building blocks named after their central activities:

1. Getting information: this part tries to capture the customer's concept by asking a lot of questions generated during preparation using a questioning framework described below.

2. Giving information: this part tries to link aspects of the customer concept and buying reasons to the supplier's product or service. The suppliers provide proofs for their statements as well as trust building measures, such as references or case studies - but always linked to the customer's concept.

3. Getting commitment: this part negotiates important customer contributions to the overall process, ensuring a win-win situation, which is central goal of the approach. Asking for contributions (e.g., to provide sample data) quickly reveals the customer's seriousness of interest.

The activity "Getting information" uses a questioning framework consisting of "Confirmation questions", "New information questions", and "Attitude questions":

- Confirmation questions: check and confirm already existing knowledge about the customer. Questions of this type use keywords like "still", "continue" or "remain". 
They are typically asked at the beginning of the session. Example: "Do you still use Form A to gather client data?"

- New information questions: collect new aspects of the customer's concept. They use keywords like "explain", "describe", or "elaborate". Example: "Could you please elaborate on what you call 'lodgment'?"

- Attitude questions: go beyond technical details by asking for attitudes, feelings, and preferences. Keywords are "attitude", "feeling", "think" or "prefer". Example: "What do you think of the company X, a supplier of tools you look for?"

In addition to the questioning framework, Conceptual Selling ${ }^{\circledR}$ uses a technique named "Golden Silence". Here, a sales person asks a question and then uses three or four seconds of silence afterwards. When faced with Golden Silence, buyers often start sharing valuable insights they would have not mentioned otherwise.

\subsection{The Green Sheet}

The Green Sheet is the Conceptual Selling ${ }^{\circledR}$ tool. It is basically a spread sheet and helps preparing the customer session. It provides structure and guidance for the abovementioned parts (cf. Figure 2):

- The Buying Influencers are the ones impacting the decision making. If the attendees do not have any influence on the buying decision then obviously the wrong people are present.

- The Valid Business Reason describes what the customer wants to fix, avoid or achieve. If there is no discrepancy of any kind then it has to be carefully decided whether to continue or even start with the session.

- The Credibility prepares measures to engage the lack of trust. Typical items here are case studies or references where similar problems have been solved successfully.

- The Single Sales Objective is written from a seller's perspective describing the business opportunity with the customer at hand.

- The Giving and Getting Information as well as Getting Commitment were already described in the previous section.

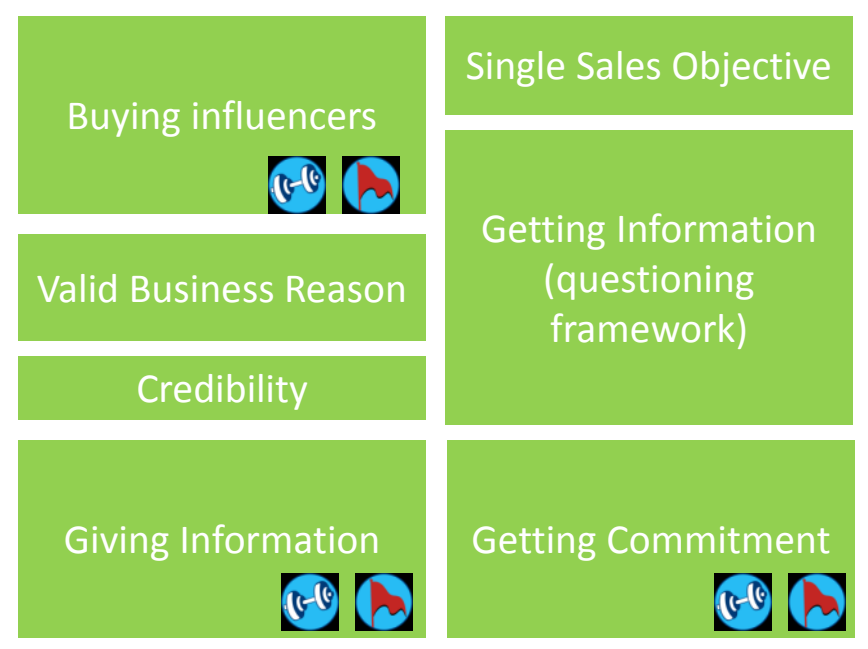

Figure 2. Section overview of the Miller Heiman Green Sheet: Particular strengths (e.g., a certain product feature meeting the customer's need) are marked by weights while problems or difficulties (e.g., a certain customer attitude or behavior) are indicated using red flags. Especially red flags have to be resolved. 
The Green Sheet is filled during the preparation for the sales session. Substantial problems (e.g., wrong attendees, no business reason, no clear sales objective) as described above represent exit criteria and will cause the seller to quit the sales process.

\subsection{Secondary Risks}

While Conceptual Selling ${ }^{\circledR}$ and its tool introduce typical risk responses to the pre-sales challenges, it also introduces secondary risks especially from a requirements engineering perspective [4]. Secondary risks are risks introduced by applying certain risk responses [11]. They can also be called side-effects. For instance, the Green Sheet captures the customer concept, but its original version does not capture an integral part of it: the customer's language. This gap can be closed by using glossaries. Further, the Green Sheet does not contain a documentation guideline on how to record the customer concept. Here, user stories [12] may help to find a standard format. Another aspect, the Green Sheet does not regard, is scoping. This especially has to be considered as part of the questions (Getting Information). Last but not least, with its questioning framework, the Green Sheet only captures Kano performance attributes [13]. Especially introducing the risk of leaving aside Kano basic attributes might cause tremendous extra effort later on. However, it is hard to conduct observational studies to capture these attributes in the pre-sales phase. Therefore the emphasis is on fair and valid assumptions.

\subsection{Summary}

This chapter introduced the Miller Heiman sales approach and the Green Sheet in a brief overview. Potential shortcomings were outlined in addition to how they can be resolved usually by standard RE measures. Miller Heiman provides many measures to encounter the presales phase's specific risks. It also introduces a measure only specific to sales: exit criteria. They especially help preserving the pre-investment. Both (measures and risks) are summarized in Table 2 below. Table 2 also reveals a conceptual problem: this risk of moving targets is not addressed by Miller Heiman. And it is not well addressed by requirements engineering, either.

\section{Catching the Moving Target - The Box Fight Analogy}

As shown in the previous section, Miller Heiman's sales approach tries to capture the customer concept involving a lot of preparation and checks. Yet, the customer concept, or the solution it requires, might be a steadily moving target (see pre-sales risks). This especially occurs when the customer asked for consulting and has only dealt with a topic for a short period of time, i.e., s/he is in the very early stages of seeking a solution. Yet, if the discrepancy is clear, this is the ideal situation for value selling. On the contrary, moving targets are rarely found as part of a RfP since the wanted solution here has been thought over quite some time (maybe even by the competitor).

Pre-sales is not the only activity dealing with moving targets. Far away from sales, for example, audio signals change constantly. They are digitized using many little probes applied by a higher sampling frequency. If the signal was not changing only a single probe would be sufficient. Hence coping with change requires many small steps.

Another very famous set of approaches embracing change or moving targets are agile development frameworks like Scrum [14]. They use short iterations to create small but working increments. Then they check together with the customer if they are still heading towards the right direction. If they do not, they make adaptations.

Thinking of short iterations or small steps also reminds of the following:

"Lord, I'm not praying for miracles and visions,

I'm only asking for power for my days.

Teach me the art of small steps! 
Make me clever and witty among the diversity of days

to be able to record important recognitions and experiences!

Help me prioritize to use my time accurately!

Present me with safe senses to be able to judge whether a thing is first rank or second rank priority!

I pray for power for discipline and moderation, not only to

run through my life, but also to live my days reasonably, and

observe unexpected pleasures and heights!

Save me from the naive belief that everything goes smoothly in life!

Present me with the sober recognition that difficulties,

failures, fiascos, set-backs are additional elements given

by life itself that make us grow and mature. [...]" (A Prayer by Antoine de Saint-Exupéry)

Sounding like the mentor of agile methods or like the solution to moving targets in the presales phase, Antoine de Saint-Exupéry also obviously suggests to anticipate change and to use small steps as a response. The question remaining is how to integrate the idea into the overall approach.

Table 2. Pre-sales risks, their partial coverage by the Miller Heiman sales approach, and their exit criteria

\begin{tabular}{|c|c|c|}
\hline Risk & Measure & Exit criteria \\
\hline Pre-investment & $\begin{array}{l}\text { Definition of exit criteria, i.e. when to quit } \\
\text { the pre-sales phase. }\end{array}$ & Quit when any of the other exit criteria is met \\
\hline Competition & $\begin{array}{l}\text { Supports value selling and customer } \\
\text { individual offers, differentiation by linking } \\
\text { product or service features to parts of } \\
\text { the customer concept. }\end{array}$ & $\begin{array}{l}\text { Quit when there is no way to differentiate from } \\
\text { competition and there is a reduction to price which } \\
\text { undermines the required win-win situation. }\end{array}$ \\
\hline Large unknown & $\begin{array}{l}\text { Strong focus on preparation. } \\
\text { Questioning framework. Priorities are } \\
\text { used to focus on the most important } \\
\text { issues. }\end{array}$ & $\begin{array}{l}\text { Quit when there is no sufficient customer commitment } \\
\text { to find answers to reduce the unknown. } \\
\text { No provision of data or extra material by the customer. }\end{array}$ \\
\hline Lack of trust & $\begin{array}{l}\text { Credibility and trust building measures } \\
\text { (cf. Green Sheet). }\end{array}$ & $\begin{array}{l}\text { There are basic issues disturbing the relationship that } \\
\text { cannot be resolved during the session. }\end{array}$ \\
\hline $\begin{array}{l}\text { Attitude \& feelings, phase } \\
\text { fragility }\end{array}$ & $\begin{array}{l}\text { Attitude questions as part of the } \\
\text { questioning framework help identify } \\
\text { basic issues that have to be resolved. }\end{array}$ & $\begin{array}{l}\text { Quit when there are attitudes that contradict the } \\
\text { current business approach. Significant basic issues } \\
\text { that cannot be resolved. }\end{array}$ \\
\hline Limited time & $\begin{array}{l}\text { Strong focus on preparation and } \\
\text { priorities. }\end{array}$ & $\begin{array}{l}\text { Quit when customer is unable to name priorities; } \\
\text { insufficient time }\end{array}$ \\
\hline Moving target & (Not addressed) & (Not addressed) \\
\hline $\begin{array}{l}\text { Wrong people, unknown } \\
\text { organization \& decision } \\
\text { making }\end{array}$ & $\begin{array}{l}\text { Buying influencer analysis and } \\
\text { questioning framework during } \\
\text { preparation. }\end{array}$ & $\begin{array}{l}\text { Quit when there are no participants available to } \\
\text { answer the commitment questions. } \\
\text { Quit when no participant is involved in the decision } \\
\text { making process. }\end{array}$ \\
\hline Seriousness of interest & $\begin{array}{l}\text { Customer commitment monitoring, } \\
\text { questioning framework. }\end{array}$ & $\begin{array}{l}\text { Quit when there is insufficient commitment. } \\
\text { Quit when no discrepancy can be found. }\end{array}$ \\
\hline Wrong timing & $\begin{array}{l}\text { Central focus of Miller Heiman Strategic } \\
\text { Selling®; Preparation identifies } \\
\text { discrepancy and business reason. }\end{array}$ & $\begin{array}{l}\text { Quit when there is no discrepancy or no valid } \\
\text { business reason. }\end{array}$ \\
\hline Incomprehensible (only RfP) & Only RfP & $\mathrm{n} / \mathrm{a}$ \\
\hline $\begin{array}{l}\text { Predefined solution (only } \\
\text { RfP) }\end{array}$ & Only RfP & $\mathrm{n} / \mathrm{a}$ \\
\hline $\begin{array}{l}\text { No customer access (only } \\
\text { RfP) }\end{array}$ & Only RfP & $\mathrm{n} / \mathrm{a}$ \\
\hline Bargaining/Negotiation & Stay win-win, definition of exit criteria. & Quit once the win-win situation is gone. \\
\hline Reduction to price (only RfP) & $\begin{array}{l}\text { Only RfP; Miller Heiman focuses on } \\
\text { value selling and differentiating from } \\
\text { competitors }\end{array}$ & Quit once the win-win situation is gone. \\
\hline
\end{tabular}




\subsection{The Box Fight Analogy}

Another inspiring and helpful idea incorporating small steps stems from the fact that conventional requirement engineers will be "knocked out" in the pre-sales phase like a boxer during a fight. The reasons for this knock out especially are the moving target, limited customer access, limited time, and the limited degree of detail. The Box Fight Analogy [6] extends the pre-sales requirements engineering grounding on Miller-Heiman's sales approach introducing the concept's means to tackle moving targets. Here, the customer concept and its direction, which starts out as a set of assumptions, is constantly checked, refined, and amended as the customer session (i.e., the box fight) evolves (cf. Figure 3).

Already on first sight, box fights seem to fit well into the world of sales and marketing where there are also terms like war rooms and battle cards. Thinking of box fights produces a rich imagery: the box ring, the bell, two opponents, the coaches, etc. The most obvious commonalities with the pre-sales phase are the limited time and the moving target: In box fights the next sound of the bell is only a few minutes away. Only during that time the boxer may strike or to knock out the opponent. The latter is constantly moving trying to do the same. Indicated by the bell ring there are breaks in-between which the coaches and their fighters use to check and rearrange their initial strategy (taking small steps and adapt). The goal to win the fight always remains. Yet, for instance, the boxer might have to punch a little lower or use the other fist to hit a newly identified weak spot. The initial strategy was setup even before the fight started, e.g., by video analysis of the opponent. But it gets adapted during breaks as more facts have become known.

As in sales there are phases of preparation, fighting, and rearrangements. The fight is over when the time elapsed, the opponent is knocked out (i.e., the moving target is not moving any longer), or when the coach throws the towel indicating s/he wants to quit the fight (which basically corresponds to meeting one of the above mentioned exit criteria).

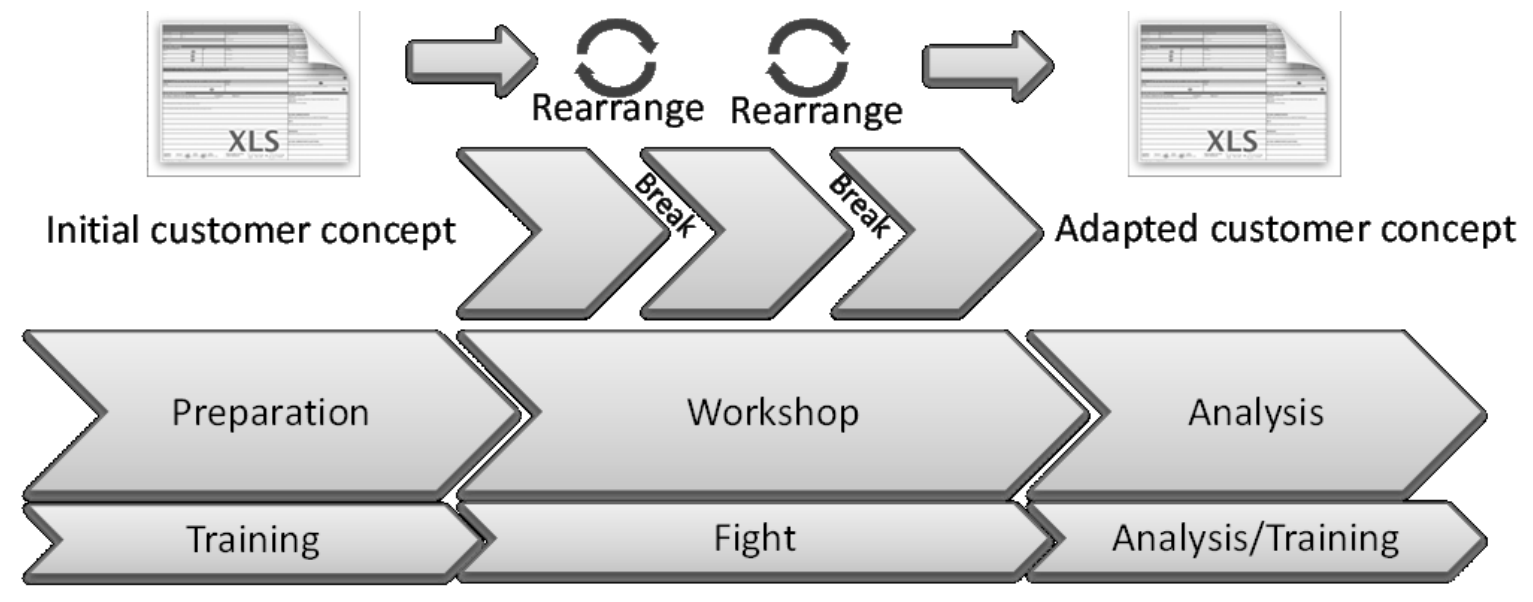

Figure 3. An overview of the overall process from preparation to analysis

\subsection{Fighter, Coach, Opponent \& Referee - The Roles}

Inside the Box Fight Analogy there are roles to be translated to the pre-sales scenario: the fighter, the coach, the opponent, and the referee. In pre-sales sessions, the fighter is the person doing the talking or moderating of the sessions. As real-world boxers $\mathrm{s} / \mathrm{he}$ is the one actively engaging the moving target. The fighting is based on the prepared initial version of the customer concept (i.e., the result of the preparation phase, see below). The fighter uses the abovementioned session phases of Getting Information, Giving Information, and Getting Commitment in a conversation with the customer asking the prepared questions to gain the knowledge and insights needed. 
The coach is somebody equally skilled as the fighter, maybe a little more experienced. Her/his main task is to listen and observe to the conversation with the customer which corresponds to watching the fight. $\mathrm{S} / \mathrm{he}$ is the one to take notes and to make adaptations and amendments to the concept if needed. During breaks $\mathrm{s} /$ he informs the fighter if a strategy change is required. Or $\mathrm{s} / \mathrm{he}$ even takes over the "fighting" herself/himself if required - which, however, is unlikely to happen in real box fights. Consequently, workshops need to be attended by at least two people from the potential supplier in order to catch every new piece of information and every change in direction to properly address the moving target challenge. No one can listen, write, and talk at the same time.

Next: the opponent. Here, it is important to know that the customer is not the opponent! The last thing suppliers want is to knock out their customers. It is the moving target solution which needs to be caught! In order to be able to capture it, customers have actually a twofold role: On the one hand they are actually part of some kind of extended coaching team providing hints and information to stop the target from further movements. On the other hand, they are the referee who knows when the opponent is down for the count.

\subsection{Training, Fighting, Analyzing - The Phases}

In box fights there are three phases which can be translated to pre-sales customer sessions (cf. Figure 3): the preparation (or training), the session itself (the fight), and its analysis thereafter.

During the preparation phase the initial customer concept is created which corresponds to initially filling the Green Sheet with already known information (i.e., taken from a Blue Sheet [7] used for account analysis). This information is used to compile confirmation questions (for assumptions), new information questions (for the unknown), and attitude questions (for the customer's mood and feelings). The questions are grouped by topic and topics are ordered by (assumed) customer priorities. The preparation phase should conclude with a risk assessment and a decision whether to continue or to quit the process (i.e., a decision gate checking the exit criteria). The fight may begin only when passing this decision gate.

As in boxing, the customer session (aka the fight) is structured as a sequence of rounds and breaks. A round follows the typical pre-sales requirements engineering cycle pattern of Getting Information, Giving Information, and Getting Commitment. It uses the prepared customer concept and questions as conversation guidelines. During the session a lot of information is gathered, which either has to be integrated into the existing concept or requires a change in direction. Breaks are used to verify priorities and rearrange the concept and the session's direction if necessary. Actually, they even serve multiple purposes at the same time: they allow rearrangements, but also gathering feedback from individual participants thus gaining insights the suppliers would not have heard of from a larger auditorium (e.g., due to peer-pressure). This information is especially used to feed the buying influencer analysis (see Green Sheet in Section 3.2). To find supporters (preferably on multiple levels) for the supplier's solution is a very important sales activity [5].

Finally, when the customer session is over, its analysis finalizes the customer concept and prepares it to serve as a basis for effort estimations and price indications. Another important task from now on is to monitor customer commitment and to help improving the overall approach.

\subsection{Throwing the Towel - The Exit Criteria}

Box fights end either when the time elapsed, the opponent is knocked out or when the coach throws the towel signaling that $\mathrm{s} / \mathrm{he}$ wishes to quit. Quitting also is a regular procedure in presales. Once defined exit criteria are met the supplier ought to quit the sales process in order to save his pre-investment. Table 3 summarizes risks, measures and exit criteria for the pre-sales phase including the ones for the moving target that was not addressed in Table 2. 
Table 3. Overview of risks, measures and exit criteria

\begin{tabular}{|c|c|c|}
\hline Risk & Measure & Exit criteria \\
\hline Pre-investment & $\begin{array}{l}\text { Definition of exit criteria, i.e. when to quit the } \\
\text { pre-sales phase. }\end{array}$ & $\begin{array}{l}\text { Quit when any of the other exit criteria is } \\
\text { met }\end{array}$ \\
\hline Competition & $\begin{array}{l}\text { Supports value selling and customer } \\
\text { individual offers, differentiation by linking } \\
\text { product or service features to parts of the } \\
\text { customer concept. }\end{array}$ & $\begin{array}{l}\text { Quit when there is no way to } \\
\text { differentiate from competition and there } \\
\text { is a reduction to price which undermines } \\
\text { the required win-win situation. }\end{array}$ \\
\hline Large unknown & $\begin{array}{l}\text { Strong focus on preparation. Questioning } \\
\text { framework. Priorities are used to focus on } \\
\text { the most important issues. }\end{array}$ & $\begin{array}{l}\text { Quit when there is no sufficient } \\
\text { customer commitment to find answers } \\
\text { to reduce the unknown. } \\
\text { No provision of data or extra material by } \\
\text { the customer. }\end{array}$ \\
\hline Lack of trust & $\begin{array}{l}\text { Credibility and trust building measures (cf. } \\
\text { Green Sheet). }\end{array}$ & $\begin{array}{l}\text { There are basic issues disturbing the } \\
\text { relationship that cannot be resolved } \\
\text { during the session. }\end{array}$ \\
\hline Attitude \& feelings, phase fragility & $\begin{array}{l}\text { Attitude questions as part of the questioning } \\
\text { framework help identify basic issues that } \\
\text { have to be resolved. }\end{array}$ & $\begin{array}{l}\text { Quit when there are attitudes that } \\
\text { contradict the current business } \\
\text { approach. Significant basic issues that } \\
\text { cannot be resolved. }\end{array}$ \\
\hline Limited time & Strong focus on preparation and priorities. & $\begin{array}{l}\text { Quit when customer is unable to name } \\
\text { priorities; insufficient time }\end{array}$ \\
\hline Moving target & $\begin{array}{l}\text { Customer sessions use breaks and a } \\
\text { team of two in order to rearrange } \\
\text { according to the moving target. }\end{array}$ & $\begin{array}{l}\text { Quit when the target moved far out of } \\
\text { scope of the potentially suggested } \\
\text { solution. }\end{array}$ \\
\hline $\begin{array}{l}\text { Wrong people, unknown organization } \\
\& \text { decision making }\end{array}$ & $\begin{array}{l}\text { Buying influencer analysis and questioning } \\
\text { framework during preparation. }\end{array}$ & $\begin{array}{l}\text { Quit when there are no participants } \\
\text { available to answer the commitment } \\
\text { questions. } \\
\text { Quit when no participant is involved in } \\
\text { the decision making process. }\end{array}$ \\
\hline Seriousness of interest & $\begin{array}{l}\text { Customer commitment monitoring, } \\
\text { questioning framework. }\end{array}$ & $\begin{array}{l}\text { Quit when there is insufficient } \\
\text { commitment. } \\
\text { Quit when no discrepancy can be found. }\end{array}$ \\
\hline Wrong timing & $\begin{array}{l}\text { Central focus of Miller Heiman Strategic } \\
\text { Selling®; Preparation identifies discrepancy } \\
\text { and business reason. }\end{array}$ & $\begin{array}{l}\text { Quit when there is no discrepancy or no } \\
\text { valid business reason. }\end{array}$ \\
\hline Incomprehensible (only RfP) & Only RfP & $\mathrm{n} / \mathrm{a}$ \\
\hline Predefined solution (only Rfp) & Only RfP & $\mathrm{n} / \mathrm{a}$ \\
\hline No customer access (only RfP) & Only Rfp & $\mathrm{n} / \mathrm{a}$ \\
\hline Bargaining/Negotiation & Stay win-win, definition of exit criteria. & Quit once the win-win situation is gone. \\
\hline Reduction to price (only RfP) & $\begin{array}{l}\text { Only RfP; Miller Heiman focuses on value } \\
\text { selling and differentiating from competitors }\end{array}$ & Quit once the win-win situation is gone. \\
\hline
\end{tabular}

\subsection{Summary}

The general concept of capturing moving targets is always the same: small steps, short iterations, or brief rounds interrupted by breaks to adapt the overall strategy. Additionally, regarding the limited time constraint, the Box Fight Analogy was introduced to extend Miller Heiman's Conceptual Selling ${ }^{\circledR}$ to form a pre-sales requirements engineering approach apt to cope with moving targets. However, it has to be mentioned that, even in direct customer contact scenarios, the target does not always have to move to the extreme. There are customers that have a very good sense of what they need and want. They often rather require some assistance to express their need. In those particular cases, the Box Fight Analogy appears not to be required. Yet, its breaks still deliver valuable insights for the buying influencer analysis. 


\section{Future Work}

As mentioned above, the Box Fight Analogy introduces a lot of imagery to the pre-sales phase. This imagery allows thinking about further steps concerning how to extend the pre-sales requirements engineering approach. For instance, customer-fighter classifications: the preparation activity of a customer session certainly reveals if the customer is somewhat hard or easy to handle. Some customers and their problems might require a true heavy weight champion, i.e., someone who is able to deal with difficult customers. Thus there may be different weight categories for fighters as the original ones from the World Boxing Organization (WBO): Heavyweight, JR-Heavyweight, LT-Heavyweight, SUP-Middleweight, and Middleweight.

Another option in the preparation area is the use of sparring partners. The purpose is to simulate and practice certain customer scenarios without a real customer but with specially trained colleagues. The goal is to prepare for real customer scenarios or to rehearse a certain sales session.

Better tool support is certainly needed. The Green Sheet needs to be adapted to accommodate moving targets, e.g., by using different tabs in the spread sheet program. Tools may also introduce easy to use means to support breaks (e.g., a timer and a bell). Another idea would be to think of a completely different type of tooling using the same concepts but away from spread sheets towards something more interactive so changes can be made easily and quickly.

\section{Conclusions}

The pre-sales phase is an exciting place to be for requirements engineering professionals. Yet, they have to be careful not to be "knocked out" by its conditions and challenges. This article filled the gap of a missing pre-sales requirements engineering approach. It also outlined its differences to conventional or post-sales RE. Starting on how customers are typically engaged and deriving the pre-sales phase's challenges led to finding a feasible way for pre-sales requirements engineering grounding on Miller Heiman sales approach. The latter had to be extended by further RE techniques and the Box Fight Analogy to especially meet the needs of constantly moving targets.

This article presented central ideas put into practice based on experience. There are certainly many different ways to actually do so with a specific customer. Pre-Sales RE has a strong focus on preparation and securing the pre-investment situation. Customer sessions may use a box fight setup explicitly or in a more covert fashion simply by using a little more breaks. Yet, there are also customers that really appreciate the use of clear breaks to rearrange their own ideas themselves. When to make breaks and how long strongly depends on the overall duration of the session and thus has to be adapted to the particular context.

As with pre-sales requirements engineering overall, there are some aspects that are especially new to requirement engineering professionals: they might have not been exposed to such time constraints, limited customer access, and explicitly asking for attitudes and feelings. Others might be unfamiliar with such a strong emphasis on preparation for a customer session. Defining exit criteria surely adds a new dimension as well. Yet, more importantly, RE in the pre-sales phase becomes a true team activity that has to be practiced to unfold its value-with the downside being a higher pre-investment to be protected.

\section{References}

[1] M. Glinz. (2014, May). A glossary of requirements engineering terminology. Version 1.6, Standard Glossary for the CPRE studies and exam [Online]. Available: 
http://www.ireb.org/content/downloads/1-cpre-glossary/ireb_cpre_glossary_16_en.pdf (accessed June 28, 2015).

[2] K. Pohl and C. Rupp, "Requirements Engineering Fundamentals," in A Study Guide for the Certified Professional for Requirements Engineering Exam - Foundation Level IREB compliant, 2015.

[3] K. Breiner, M. Gillmann, A. Kalenborn, and C. Müller. "Requirements engineering in the bidding stage of software projects - a research preview," in REFSQ 2015, LNCS 9013: pp. 270-276. http://dx.doi.org/10.1007/978-3-319-16101-3_19

[4] C. Oemig. "Pre-sales requirements engineering based on Miller Heiman's sales approach," in REFSQ 1st International Workshop on Requirements Engineering for the Precontract Phase (RE4P2), 2014, pp. 40-45.

[5] R. Miller, S. Heiman, and T. Tuleja, The New Conceptual Selling. 2nd Edition. Kogan Page, 2011.

[6] C. Oemig. "The box fight analogy: a blueprint for pre-sales requirements engineering workshops," in REFSQ 2nd International Workshop on Requirements Engineering for the Precontract Phase (RE4P2), 2015, pp. 71-76.

[7] R. Miller, S. Heiman, and T. Tuleja, "The New Strategic Selling," 3rd Edition, Kogan Page, 2011, pp. 288.

[8] A. Ross and M. Tyler, "Predictable Revenue: Turn Your Business Into A Sales Machine With The \$100 Million Best Practices Of Salesforce.com," Peeble Storm Press, 2011.

[9] B. Paech, R. Heinrich, G. Zorn-Pauli, A. Jung, and S. Tadijky. "Answering a request for proposal - challenges and proposed solutions," in REFSQ 2012, pp 16-29. http://dx.doi.org/10.1007/978-3-642-28714-5_2

[10]T. Searcy, "RFPs Suck! How to Master the RfP System Once and for All to Win Big Business," Channel V Books, 2009.

[11] PMI, "A guide to the project management body of knowledge," PMBOK (5. Ed), Project Management Journal, 2013. http://dx.doi.org/10.1002/pmj.21345

[12]M. Cohn, User Stories Applied: For Agile Software Development (1. Ed.) Addison \& Wesley 2004.

[13] N. Kano, S. Tsuji, N. Seraku, and F. Takahashi, "Attractive quality and must-be quality", Quality - The Journal of the Japanese Society for Quality Control, vol. 14, nr. 2, pp. 3944, 1984.

[14] K. Schwaber. "SCRUM development process," in OOPSLA 1995 Workshop Proc., 1995, pp. 117-134. http://dx.doi.org/10.1007/978-1-4471-0947-1_11 